\title{
Snow-accumulation variability from seasonal surface observations and firn-core stratigraphy, eastern Wilkes Land, Antarctica
}

\author{
IAN D. GOODWIN \\ Australian Antarctic Division, Kingston, Tasmania 7050, Australia
}

\begin{abstract}
Annual accumulation records were derived from two firn cores drilled at GD03 $\left(69^{\circ} 00^{\prime} \mathrm{S}, 115^{\circ} 30^{\prime} \mathrm{E}, 1835 \mathrm{~m}\right)$ and GD15 $\left(69^{\circ} 00^{\prime} \mathrm{S}, 130^{\circ} 48^{\prime} \mathrm{E}, 2155 \mathrm{~m}\right)$, which are separated by $750 \mathrm{~km}$ along the $2000 \mathrm{~m}$ contour in eastern Wilkes Land. The accumulation records, spanning the period 1930-85, show that annual accumulation has increased by $25 \%$ from 1960 to 1985 , resulting in the highest accumulation rates in the 55 year records. Annual accumulation layers were identified in the firn cores using a firn-stratigraphic model (based on the observed characteristics and variability of the seasonal snow-surface layer) together with seasonal oxygen-isotope ratios. The accumulation records support other evidence for a similar recent increase across Antarctica. The greater increase over the long-term mean for 1930-85 in eastern Wilkes Land was observed at GD15 which is located on a northeast aspect slope near Terre Adélie. It is suggested that the increase is the result of changes in the general atmospheric circulation pattern which have produced a higher annual frequency of precipitation events.
\end{abstract}

\section{INTRODUGTION}

An objective of the International Antarctic Glaciological Project (IAGP) over the past decade has been to measure and define the surface mass input to the Wilkes Land region of East Antarctica. As part of the IAGP, a 4 year spatial accumulation record (1981-85) was obtained in eastern Wilkes Land from cane measurements made along a $750 \mathrm{~km}$ traverse route by the Australian National
Antarctic Research Expeditions (ANARE). The route follows lat. $69^{\circ} \mathrm{S}$ between long. $112^{\circ}$ and $131^{\circ} \mathrm{E}$ (Fig. 1) and approximately follows the $2000 \mathrm{~m}$ contour in a moderate accumulation zone dominated by katabatic winds. The author (Goodwin, 1990) previously reported the spatial snow accumulation and surface micro-relief distributions for eastern Wilkes Land, together with the mesoscale processes controlling these distributions.

A shallow $(30-40 \mathrm{~m})$ firn-core stratigraphy study was

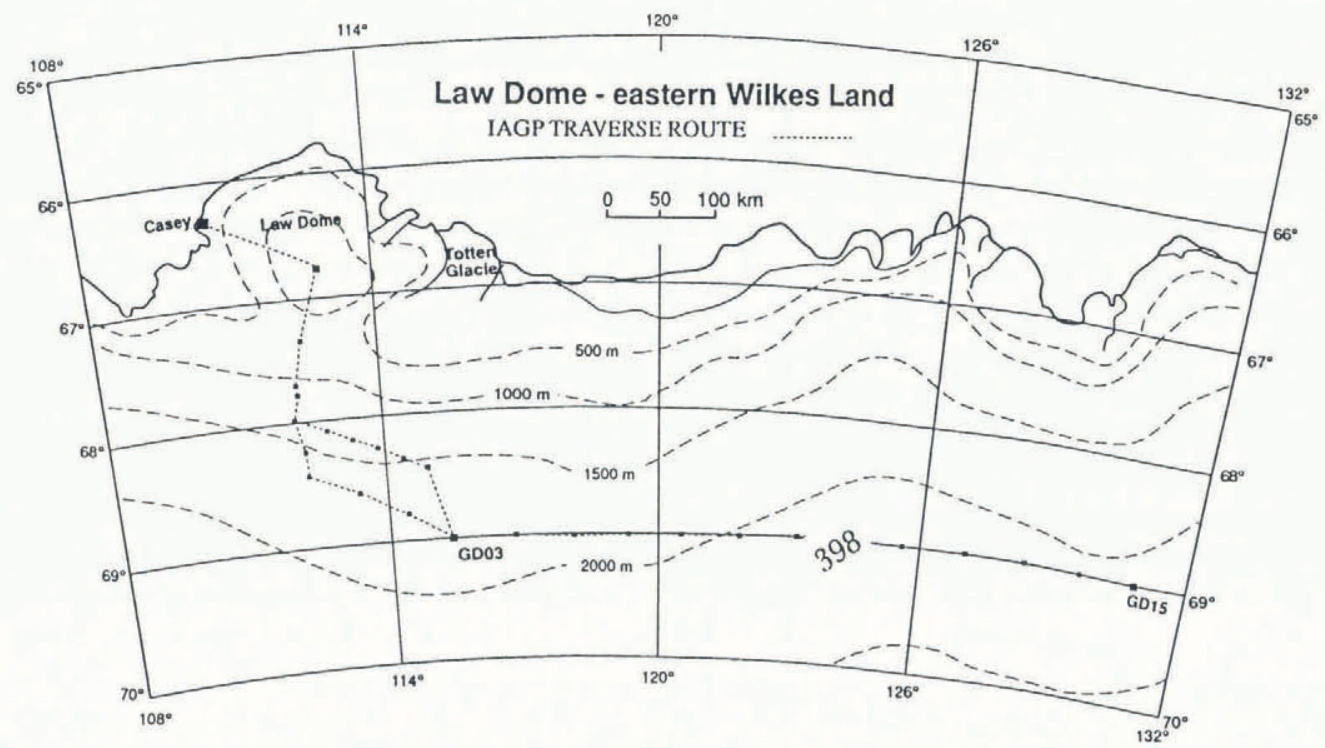

Fig. 1. Location map of eastern Wilkes Land showing the two firn-core sites at GD03 and GD15 together with the ANARE traverse route. 
carried out in 1985 to determine the temporal accumulation record over the last 50 years at two sites along the $2000 \mathrm{~m}$ contour in eastern Wilkes Land. The two sites were located at GD03 $\left(69^{\circ} 00^{\prime} \mathrm{S}, 115^{\circ} 30^{\prime} \mathrm{E}, 1835 \mathrm{~m}\right)$ and GD15 $\left(69^{\circ} 00^{\prime} \mathrm{S}, 130^{\circ} 48^{\prime} \mathrm{E}, 2155 \mathrm{~m}\right)$ (Fig. 1). A study of surficial processes, snow-accumulation variability and seasonal firn stratigraphy was carried out at GD03 to estimate the variation in the horizontal extent and vertical thickness of the annual layer due to surface micro-relief or roughness. The results of this snow-surface study are presented here together with a firn stratigraphic model for eastern Wilkes Land. The model was applied to the two firn cores from GD03 and GD15. The resulting 55 year (1930-85) annual accumulation records are discussed with respect to temporal variability and are compared to other recent short-term accumulation records across Antarctica.

\section{SEASONAL DEVELOPMENT OF THE SURFACE SNOW LAYER}

A cane farm comprising 100 bamboo canes was established at GD03 to define snow-surface variability, the charcteristics of the seasonal snow layer and the regional firn stratigraphic model. Two arms of 50 canes spaced at $1 \mathrm{~m}$ intervals were set up to intersect at right-angles with one arm parallel to the prevailing katabatic surface-wind direction. The snow-surface topographic profile and the net snow accumulation at each cane were determined by cane measurements during autumn, spring and summer 1985. Surface micro-relief type, size and orientation measurements, together with surface density and hardness measurements, were also made. In order to extend the measured record to cover 2 years of accumulation, a total of $212 \mathrm{~m}$ deep snow cores were drilled at $5 \mathrm{~m}$ intervals along each of the arms. These cores were measured in detail for visible stratigraphy, density and seasonal oxygen-isotope $\delta^{18} \mathrm{O}$ values.

Three distinct, seasonal snow surfaces were observed to form in autumn, spring and summer. The characteristics of each of these surfaces are found in Table 1. The autumn wind-glazed ice crust forms over a wind crust during a major hiatus in snow supply and, consequently, marks the end of the balance year. Jones (1983) attributed these ice crusts to surface melting which resulted from kinetic energy loss under strong katabatic wind flow. Beneath the wind crust is a layer of depth hoar which forms in snow deposited as surface hoar or from light snowfalls during mid-late summer (post-December). Light surface winds prevail during the summer and consequently redistribution processes are at a minimum, preserving the surface-hoar layer. Beneath the hoar layer is the summer surface which is characterized by a thin ice layer formed from the regelation of a surface-melt film caused by solar radiation during late spring to midsummer (November-December). This ice layer or radiation glaze is spatially discontinuous and its distribution is dependent upon the spring surface roughness. A windglazed crust also forms on the surface during late winter and/or spring when a hiatus in the snow supply occurs. However, the winter or spring glazes are not as well developed or as thick as the autumn glaze because precipitation is more frequent. The maximum development of the autumn glazed surface is correlated with the
Table 1. Surface-layer characteristics

Season Description

Autumn Wind-glazed ice crust, strong hardness up to $100 \mathrm{~kg} \mathrm{~cm}^{-2}$, spatially continuous, $0.9-2.0 \mathrm{~mm}$ thick glaze, opaque consisting of 2-5 layers, over wind crust up to $200 \mathrm{~mm}$ thick. Melt forms a cement, bonding snow grains, creating an opaque aggregate layer. Forms during the March-April hiatus in snow supply. Surface dominated by large friable, mobile snow dunes (barchan and longitudinal) up to 1-2 $\mathrm{m}$ high, consisting of early autumn snow.

Summer Radiation glaze, weak hardness up to $10 \mathrm{~kg} \mathrm{~cm}^{-2}$, spatially discontinuous, $0.5 \mathrm{~mm}$ thick, transparent regelation ice. Forms during mid December-mid January when maximum radiation occurs, melting a thin film over wind-laminated drift snow, originating from light December snowfalls/hoar frost. On micro-relief high points the radiation glaze forms on top of the exposed spring wind-glazed surface. Dominant snow-surface micro-relief is wind-laminated drift snow with weak ridges $100 \mathrm{~mm}$ high.

Spring Wind-glazed ice crust, strong hardness up to $40 \mathrm{~kg} \mathrm{~cm}^{-2}$, spatially discontinuous, $0.5 \mathrm{~mm}$ thick glaze over wind crust. Forms during the September-November hiatus in snow supply, following large snowfalls during June-August. Surface dominated by redistributed, friable longitudinal dunes $200-400 \mathrm{~mm}$ high.

occurrence of the strongest surface winds in autumn (Allison, 1985). Occasionally, depth-hoar layers occur in the upper $100-300 \mathrm{~mm}$ of snow dunes. The cane measurements and the oxygen-isotope values show that the majority of annual accumulation is derived from precipitation between early winter to late spring.

A standard model of firn stratigraphy was developed from the above observations and is similar to that used by Alley (1988). The firn-stratigraphy model interprets the annual autumn wind-glazed ice crust overlying the summer hoar and radiation glazed surface as the annual horizon marker.

\section{SPATIAL VARIABILITY OF SNOW-ACCUMUL- ATION RATES}

A 2 year record of annual accumulation rate, seasonal micro-relief and snowpack development was determined for the summer 1984 to summer 1986 epoch at GD03 using sequential seasonal topographic profiles obtained from the survey measurements and short-core stratigraphy across the cane farm. The mean accumulation rate for the epoch 1984-86 was $390 \mathrm{~kg} \mathrm{~m}^{-2} \mathrm{a}^{-1}$. The spatial variability (standard deviation/mean) of accumulation rate (due to 


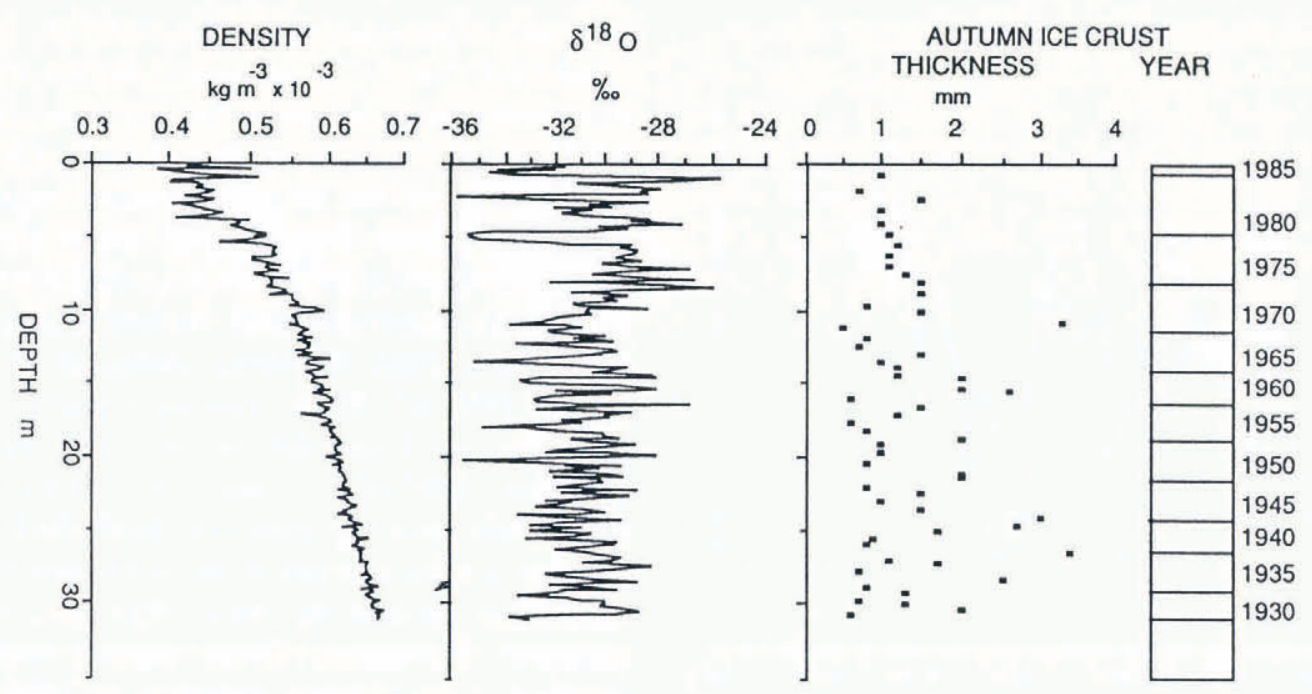

Fig. 2. GD03 density, $\delta^{18} \mathrm{O}$ and ice-crust thickness profiles together with the interpreted annual autumn ice-crust layers.

surface micro-relief or roughness) for a single-year increment was $18 \%$. The highest variability occurs during the autumn epoch when high sastrugi and barchan dunes dominate (Table 1).

\section{TEMPORAL VARIABILITY OF SNOW-ACGUMUL- ATION RATES}

Using the PICO (Polar Ice Coring Office) lightweight auger, a $31 \mathrm{~m}$ long firn core was drilled adjacent to the cane farm at GD03. The GD03 core represents 55 years of annual snow-accumulation increments which were interpreted from the combined stratigraphic analyses of density, oxygen-isotope and visible layering. A vertical profile of density, $\delta^{18} \mathrm{O}$ and the position and thickness of annual autumn ice-crust layers is shown in Figure 2. The majority of autumn ice crusts (approximately $80 \%$ ) can be matched to clear annual cycles in $\delta^{18} \mathrm{O}$ values despite the coarse sampling of $\delta^{18} \mathrm{O}$ at five samples per year. The annual snow-accumulation increments were converted to mass using the density profile (shown in Figure 2 ) to adjust for the compaction of firn layers with depth. The resulting accumulation record did not require any adjustment for the upstream accumulation gradient since this was negligible over the $2 \mathrm{~km}$ distance upstream, from which the snow originated. The mean annual accumulation rate for the period 1930-85 at GD03 was calculated as $315 \mathrm{~kg} \mathrm{~m}^{-2} \mathrm{a}^{-1}$ with an inter-annual variability (standard deviation/mean) of $24 \%$. This inter-annual variability has a larger magnitude than the single-year spatial accumulation variability of $18 \%$ measured across the cane farm because it includes additional variability due to temporal fluctuations in the precipitation regime.

A second annual accumulation-rate record was determined using the same methodology for a core at GD15 which is located $750 \mathrm{~km}$ to the east of GD03 (Fig. 1) in a similar geographic setting. A vertical profile of density, $\delta^{18} \mathrm{O}$ and the position and thickness of annual autumn ice-crust layers is shown in Figure 3. The mean annual accumulation rate for the interval 1935-85 at GD15 is $299 \mathrm{~kg} \mathrm{~m}^{-2} \mathrm{a}^{-1}$ with an inter-annual variability of $22 \%$. The annual accumulation-rate records for both

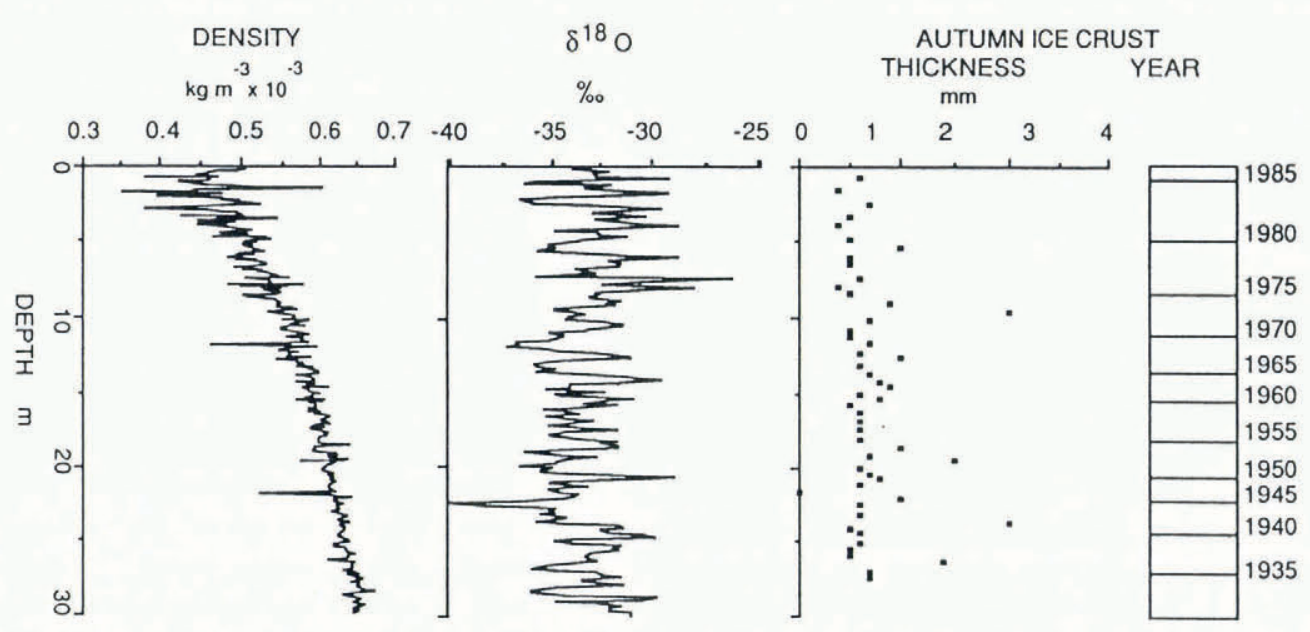

Fig. 3. GD15 density, $\delta^{18} O$ and ice-crust thickness profiles together with the interpreted annual autumn ice-crust layers. 


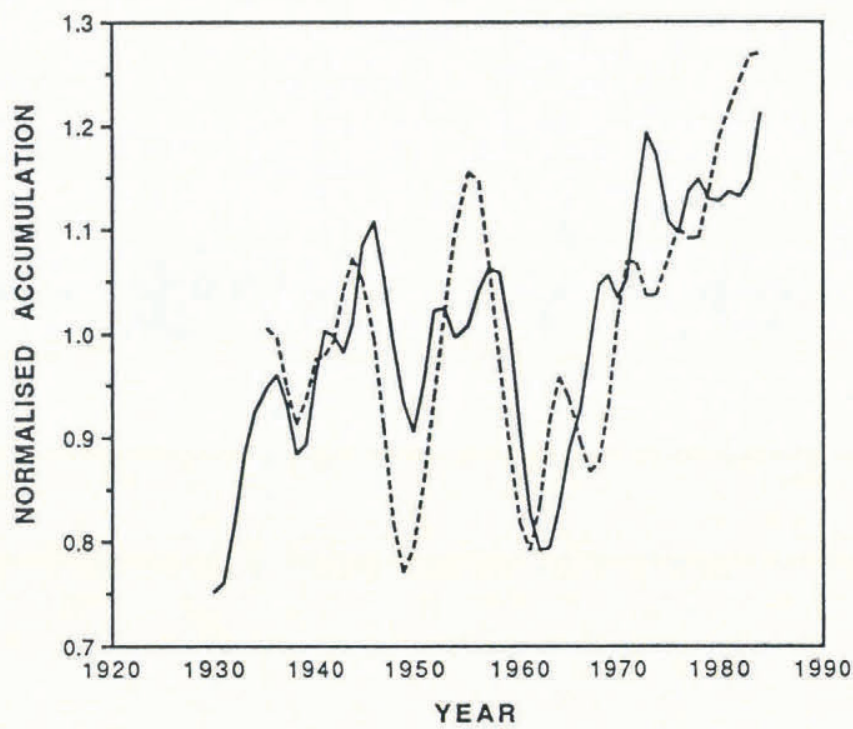

Fig. 4. Normalized and 7 year Gaussian-filtered accumulation record for GD03 and GD15 sites between 1930 and 1985. The solid line represents the GD03 record and the dashed line represents the GD15 record.

cores were normalized against the long-term mean for the 1930-85 and 1935-85 epochs, respectively. They were also filtered using a seven-point Gaussian weighted running mean to minimize the effects of spatial variability. The resulting normalized accumulation records are shown in Figure 4. The two records display good correlation indicating that they do not contain residual variability due to local effects at the sites, but rather reflect the temporal variability due to regional climatic effects across Wilkes Land. The correlation also indicates that there are not systematic errors in the independent dating of the two cores. The accumulation records display an overall increase from 1930 to 1985 with a marked decrease between 1955 and 1965, centred around 1960. Since the early 1960 s the accumulation rate has steadily increased to the mid 1980s, resulting in the highest accumulation rates in the 50 year period.

For comparison with other short-term Antarctic accumulation records, this recent trend in increasing accumulation at both sites was analysed between two epochs, 1955-65 and 1975-85, together with a comparison

Table 2. Accumulation-rate comparison

\begin{tabular}{lccc} 
Site & $\begin{array}{c}\text { Accumulation } \\
\text { rate }\end{array}$ & $\begin{array}{c}\text { Accumulation } \\
\text { change }\end{array}$ & $\begin{array}{c}\text { Accumulation } \\
\text { change }\end{array}$ \\
& $1975-85$ & $\begin{array}{c}1975-85 / \\
1955-65\end{array}$ & $\begin{array}{c}1975-85 / \\
1930-85\end{array}$ \\
& & $\%$ & $\%$ \\
\hline kg m ${ }^{-2} \mathrm{a}^{-1}$ & & \\
\hline GD15 & 355 & 23 & 15 \\
& 356 & 26 & 21
\end{tabular}

with the long-term mean for 1930-85. The results are listed in Table 2. The results show that recent accumulation rates have increased by approximately $25 \%$ since 1960 across eastern Wilkes Land. This increase is comparable to the recent increases reported in other Antarctic regions. Pourchet and others (1983) reported a general increase of $30 \%$ (with a large variability from 10 to $90 \%$ ) in accumulation for 14 sites in East Antarctica for the decade 1965-75 when compared to the previous decade 1955-65. These sites were mainly below $3000 \mathrm{~m}$ elevation in Terre Adélie but also include: Vostok $\left(78^{\circ} 28^{\prime} \mathrm{S}, 106^{\circ} 49^{\prime} \mathrm{E}\right)$, Dome C $\left(74^{\circ} 34^{\prime} \mathrm{S}, 123^{\circ} 10^{\prime} \mathrm{E}\right)$, South Pole and the Ross Ice Shelf. Peel (in press) has reported a $20 \%$ increase in accumulation since 1955 from continuous records for three firn cores drilled on the Antarctic Peninsula. These studies confirm that the observed accumulation increase in Wilkes Land is a widespread phenomenon. However, the magnitude of the regional increases across Antarctica are variable and difficult to compare accurately because of differences in reference epochs.

The autumn wind-glazed ice-crust thickness profile for GD03 shown in Figure 2 indicates a marked decrease in crust thickness since 1970 which is inversely correlated with the increase in accumulation. The greater ice-crust thicknesses observed prior to this period are not the result of temperature-gradient metamorphism as they maintain their layering integrity, which is identical to that observed for surface ice crusts. Consequently, the observed decrease in ice-crust thickness may indicate that the recent increase in annual accumulation is the result of shorter hiatus between precipitation events, especially during autumn.

Goodwin (1990) found that the GD15 region received a relatively high accumulation rate for its 2155 m elevation which was attributed to greater regional precipitation due to orographic and climatic effects. From the analysis of the long-term accumulation records in Table 2, both GD03 and GD15 have identical accumulation rates for the 197585 epoch despite the 327 m elevation difference. However, comparison of the accumulation records for the recent 1975-85 decade with those for the long-term mean (193085 ) indicates that the recent accumulation increase has been slightly (1.4 times) greater at GD15 than GD03. The relatively higher accumulation increase on the northeast aspect slope over the decade $1975-85$ is most probably due to greater regional precipitation produced by an increase in cyclonic activity. Such an increase in cyclonic activity near GD15 could result from an easterly shift or intensification in the quasi-stationary cyclonic position centred near $100^{\circ}-110^{\circ} \mathrm{E}$, north of Casey Station, (Bromwich, 1988) in the circumpolar low-pressure trough. Analysis of mean monthly (June, July and August) pressure data for the circumpolar low-pressure trough over the period 1958-89 has shown that the quasistationary cyclone near Casey Station has intensified over this period (personal communication from R. Allen, CSIRO Division of Atmospheric Research). Bromwich (1988) found that the greatest precipitation occurred to the east of the vortex centre and that the amount of precipitation was governed by cyclonic intensity. Therefore, it is consistent to interpret the recent accumulation increase and its regionality across Wilkes Land as the result of an eastward intensification of cyclonic activity. 


\section{CONCLUSIONS}

A continuous wind-glazed ice crust was observed to form on the snow surface in eastern Wilkes Land during major hiatus in snow supply during autumn. The wind-glazed ice crust was also observed as a preserved marker layer in the snowpack. This layer overlies a summer hoar layer and provided a reliable stratigraphic model together with oxygen-isotope $\left(\delta^{18} \mathrm{O}\right)$ values to interpret annual accumulation-rate records in firn cores from two sites in eastern Wilkes Land. A detailed study of the spatial variability of accumulaton rate across a cane farm at GD03 found that annual spatial variability accounts for approximately $75 \%$ of the observed inter-annual variability in the cores.

The accumulation-rate records from two sites (GD03 and GD15) span the period 1930-85 and show annual accumulation has increased by $25 \%$ from 1960 to 1985 which has resulted in the highest accumulation rates in the 55 year record. This accumulation increase across $750 \mathrm{~km}$ of eastern Wilkes Land supports evidence by Pourchet and others (1983) and Peel (in press) for a similar increase across Antarctica. The increase in annual accumulation has been greatest at GD15 (on the northeast aspect slope) where accumulation during the 1975-85 epoch is $21 \%$ higher than the long-term mean for 1930-85, compared to $15 \%$ for the same epochs at GD03 (on the northwest aspect slope). A probable explanation for the increase is a greater frequency of precipitation events due to changes in the general circumpolar atmospheric circulation pattern. The regionality of the increase in Wilkes Land may be controlled by an easterly intensification in cyclonic activity centred near $100^{\circ}-110^{\circ} \mathrm{E}$ (Bromwich, 1988) in the circumpolar low-pressure trough.

\section{AGKNOWLEDGEMENTS}

The field work was enthusiastically carried out by members of the 1985 ANARE eastern Wilkes Land glaciological traverses. The author also wishes to thank E. Wishart for assistance with the oxygen-isotope analyses and his colleagues V. Morgan and N. Young for discussion.

\section{REFERENCES}

Alley, R. B. 1988. Concerning the deposition and diagenesis of strata in polar firn. F. Glaciol., 34(118), 283-290.

Allison, I. 1985. Diurnal variability of the surface wind and air temperature at an inland Antarctic site: 2 years of AWS data. ANARE Res. Notes 28, 81-92.

Bromwich, D. H. 1988. Snowfall in high southern latitudes. Rev. Geophys., 26(1), 149-168.

Goodwin, I.D. 1990. Snow accumulation and surface topography in the katabatic zone of eastern Wilkes Land, Antarctica. Antarct. Sci., 2(3), 235-242.

Jones, D.J. 1983. Snow stratigraphy observations in the katabatic wind region of eastern Wilkes Land, Antarctica. ANARE Res. Notes 17.

Peel, D. A. In press. Ice-core evidence from the Antarctic Peninsula region. In Bradley, R. S. and P. D. Jones, eds. Climate since 1500 A.D. London, Harper Collins Academic.

Pourchet, M., F. Pinglot and C. Lorius. 1983. Some meteorological applications of radioactive fallout measurements in Antarctic snows. F. Geophys. Res., 88(C10), 6013-6020.

The accuracy of references in the text and in this list is the responsibility of the author, to whom queries should be addressed. 